\title{
Normas de Publicación
}

\section{VÍNCULOS \\ UNIVERSIDAD DE LAS FUERZAS ARMADAS ESPE}

\section{ABOUT THE JOURNAL}

"Vínculos - ESPE" is a peer-reviewed journal published 3 times a year by Universidad de las Fuerzas Armadas - ESPE. It is committed to advance theory and practice related to all forms of outreach and engagement between higher education institutions and communities. This includes, but it is not exclusive, reporting on studies of impact in the areas of public service, outreach, engagement, extension, community-based participatory research, service-learning, critically examining emerging issues, trends, challenges.

\section{TYPES OF CONTRIBUTIONS}

\section{Essays}

Perspective, opinion, and commentary that present a reflection on the impact of the experience in the personal and professional life. For instance, how this experience helped to shape your personal point of view critiquing widespread notions pertaining to a field It is recommended not to exceed 10,000 characters (with spaces)

\section{Technical Note}

Notes are short papers that present significant new observations and methodological advances. Notes may contain results that are not sufficiently elaborated or developed as to justify an article, but are still of considerable potential significance. It is recommended not to exceed 10,000 characters (with spaces)

\section{Research Article}

Detailed studies reporting original research and are classified as primary literature. They include title, abstract, introduction, methods, results, discussion/conclusion, acknowledgements, and references. It is recommended not to exceed 20,000 characters (with spaces). 


\section{Review}

synthetic overview of a subfield. These papers are expected to include discussion of new directions, new syntheses, and resolutions of old questions. It is recommended not to exceed 20,000 characters (with spaces).

\section{Press release}

Short science news articles to communicate important information to decision-makers, practitioners, and public in general. It increases awareness of science in the public domain and a broad appreciation of scientific progress, increases awareness of specific scientific projects, instruments or organization missions. It is recommended not to exceed 600 characters (with spaces).

\section{PREPARING YOUR PAPER}

\section{Style Guidelines}

Papers must be written in Spanish or American English and should follow the style guidelines described in the Publication Manual of the American Psychological Association (6th ed.) Merriam-Webster's Collegiate Dictionary (11th ed.) should be consulted for spelling

\section{Formatting and Templates}

Papers may be submitted in Word. Figures should be saved separately from the text. The main document should be single- spaced, with one-inch margins on all sides, and all pages should be numbered consecutively. Text should appear in 11 -point Times New Roman.

\section{Checklist: What to include}

1. Author Details. Please include all authors' full names, affiliations, postal addresses, and email addresses on the cover page. Where appropriate, please also include social media handles (Facebook, Twitter or Linkedln). One author will need to be identified as the corresponding author, with their email address normally displayed in the published article.

2. Abstract. This summary of your article is normally no longer than 200 words.

3. Keywords. Keywords are the terms that are most important to the article and should be terms readers may use to search. Authors should provide 5 to 7 keywords.

4. Body of Manuscript. Please follow the type of contribution description.

5. Supplemental Material. High quality photos (600 dpi for black \& white art and 300 dpi for color) are encouraged to be submitted as supplemental material. This material will be used as illustration in the production of the journal. The photos will inspire and engage the reader. 
6. Figures. Figures should be high quality $(600$ dpi for black \& white art and $300 \mathrm{dpi}$ for color). Figures should be saved as TIFF, PostScript or EPS files. Figures embedded in your text may not be able to be used in final production. Include a title or caption for each figure (please follow APA formatting). You clarify if the figure/illustration is a reproduction of a previously published image and include an acknowledgement to this effect.

7. Tables. Please supply editable table files. We recommend including simple tables at the end of your manuscript, or submitting a separate file with tables. Tables should have descriptive titles, consecutive numbers, and headings for all columns; do not use vertical lines in the body of the table.

8. Equations. If you are submitting your manuscript as a Word document, please ensure that equations are editable.

\section{Author Agreement/Use of Third-Party Material}

Authors are responsible for obtaining permission to reproduce copyrighted material from other sources. As an author, you are required to secure permission if you want to reproduce any figure, table or extract text from any other source. This applies to direct reproduction as well as "derivative reproduction" (for which you have created a new figure or table which derives substantially from a copyrighted source).

\section{Submitting Your Paper}

Please read the guidelines above and then submits your paper in our website journal.espe.edu.ec

\section{Our publication policies}

Our detailed publication policies can be found in the Editorial and Publishing policies file [http://journal.espe.edu.ec/index. php/vinculos].

Our compiled policies cover various topics like conflict of interest, authorship, copyright and license policies. A summary of the main policies are below.

We will follow recommendations by the Committee on Publication Ethics (COPE) https://publicationethics.org/

All articles are subject to peer review before they can be accepted for publication. The acceptance criteria for all papers are the quality and originality of the research and its significance to journal readership.

All articles published by "Vinculos-ESPE" are made freely and permanently accessible online immediately upon publication, without subscription charges or registration barriers.

There are no page charges for publishing in "Vinculos-ESPE".

In case of any questions, please contact the editors 


\section{ABOUT VÍNCULOS ESPE}

- Vínculos ESPE is a publication of Universidad de las Fuerzas Armadas ESPE.

- Vínculos - ESPE is a peer-reviewed journal published 3 times a year dedicated to the promotion of the diversity of interactions between technology, science and society.

- The journal is available online at http://journal.espe.edu.ec/index.php/vínculos. Please visit the site for submission instructions and latest information.

- If you have any questions, do get in touch with the central office at vínculos@espe.edu.ec

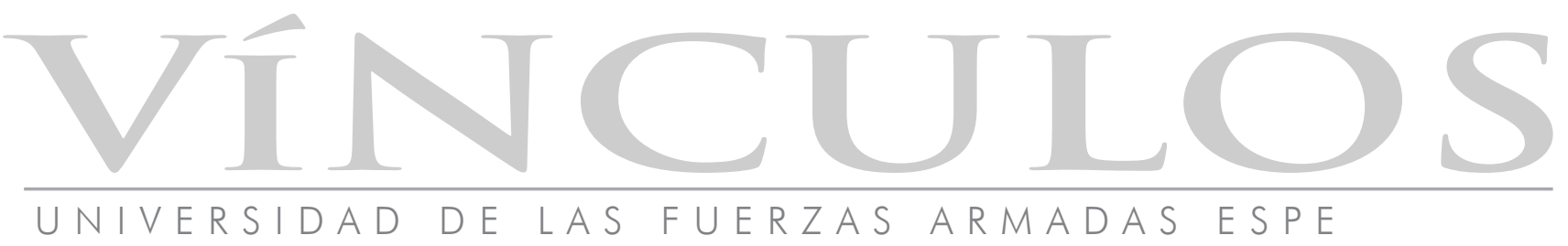

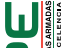

บำin:

W!閚

(두용 